\title{
Microorganism population, theobromine, antioxidant, and FTIR analysis of Samarinda cocoa bean fermented with Saccharomyces cerevisiae and Acetobacter aceti
}

\author{
1, *Rahmadi, A., ${ }^{1}$ Yunus, Y., ${ }^{1}$ Ulfah, M., ${ }^{1}$ Candra, K.P. and ${ }^{2}$ Suwasono, S. \\ ${ }^{1}$ Department of Agricultural Products Technology, Faculty of Agriculture, University of Mulawarman, \\ Indonesia \\ ${ }^{2}$ Department of Agricultural Products Technology, Faculty of Agricultural Technology, University of \\ Jember, Indonesia
}

\author{
Article history: \\ Received: 20 April 2020 \\ Received in revised form: 31 \\ May 2020 \\ Accepted: 8 June 2020 \\ Available Online: 27 July \\ 2020
}

Keywords:

Acetobacter aceti,

Cocoa bean fermentation, FTIR,

Saccharomyces cerevisiae, Theobromine

DOI:

https://doi.org/10.26656/fr.2017.4(6).178

\begin{abstract}
This research aimed to observe $S$. cerevisiae and A. aceti induced fermentation of cocoa bean from Samarinda, Indonesia, in comparison to commercial cocoa bean in terms of microbial population, $\mathrm{pH}$, total acids, total phenols, theobromine, antioxidant capacity, and FTIR profile. Cocoa beans were fermented with a boxed fermentation method resembling commercial plantation for four days at ambient box temperature $\left(35-40^{\circ} \mathrm{C}\right)$. Four fermentation samples were produced which were spontaneous, 2\% Saccharomyces cerevisiae, Acetobacter aceti, or mixed culture (S. cerevisiae and A. aceti) induced fermentations. Total Plate Count (TPC) and Total Yeast-Mold (TYM), pH, total phenol, theobromine, antioxidant activity, and FTIR analyses were performed according to the established method. There was no significant difference in the microbe population in all fermented cocoa. Mixed culture fermented cocoa had a slightly lower final $\mathrm{pH}$. $S$. cerevisiae fermented cocoa produced the highest total phenol compared to the same compound content in other fermented cocoa. The mixed culture fermented cocoa had better theobromine content $162.3 \pm 22.6 \mathrm{ppm}$, antioxidant capacity $424.9 \pm 3.3 \mathrm{ppm}$, and the closest theobromine and caffeine identification zones to commercial cocoa samples. The use of mixed culture of $S$. cerevisiae and $A$. aceti is suggested as the better inoculum to ferment cocoa bean at local farms.
\end{abstract}

\section{Introduction}

The cocoa bean is a popular research subject considering its strong antioxidant capacity and indulged taste. Various techniques of fermentation of cocoa bean in commercial plantation allow standardized but distinct products. The local cocoa bean farmers in Indonesia commonly did not conduct fermentation but only drying. This problem results in lower quality of the cocoa bean. In combination with less compliant to good agricultural practice, the cocoa bean from local Indonesian farmers is not internationally competitive (Rahmadi and Fleet, 2008).

Researchers introduced and implemented the use of culture cocktail to ferment the cocoa bean in large plantations (Cempaka et al., 2014; De Vuyst and Weckx, 2016; Meersman et al., 2016). It is essential to use a straightforward but widely available culture source to introduce simple but successful fermentation of cocoa beans to local farmers (Meersman et al., 2015).
Therefore, baker's yeast (Saccharomyces cerevisiae) and acetic acid (cuka) starter (Acetobacter aceti), locally available in Samarinda, Indonesia, were selected as strong microbial cocktail candidates.

Of all parameters observed, this research employs a Fourier Transformed Infra-Red (FTIR) analysis that produces a unique profile. Therefore, it is proposed to be a fast but reliable method to detect high quality of cocoa bean fermentation. The FTIR has an identification regiment at wavelengths of 600 to $1500 \mathrm{~cm}^{-1}$ (Altemimi et al., 2017). The identification regiment can approximate identical covalent binds when comparing measurement results from two different samples (Koch et al., 2013). Therefore, a similar quality of fermented cocoa bean can be identified.

This research aimed to observe $S$. cerevisiae and $A$. aceti induced fermentation of cocoa bean from Samarinda, Indonesia, in comparison to commercial cocoa bean in terms of microbial population, $\mathrm{pH}$, total 
acids, total phenols, theobromine, antioxidant capacity, and FTIR profile.

\section{Materials and methods}

\subsection{Materials}

Method of fermentation was learned from PT Perkebunan Nusantara (Nusantara Plantation XIII in Jember, Indonesia in January-February 2018. The techniques obtained from commercial plantation were then employed to local farmers in Samarinda, Indonesia, in April-December 2018. Instant Saccharomyces cerevisiae (Fermipan, Indonesia) and Acetobacter aceti (Segiri Market, Samarinda) and were used to induce fermentation on Samarinda cocoa beans for four days, with a boxed fermentation method resembling commercial plantation. The starter inoculum was used at a concentration of $2 \%(\mathrm{v} / \mathrm{w})$. Therefore, it was either a $2 \%$ concentration for single culture inoculum or $1 \%$ each for in the mixed culture inoculum of $S$. cerevisiae and $A$. aceti. The observed parameters were measured on day- 4 of the fermentation period, while the FTIR measurements were conducted on the initial day and final day of fermentation. For FTIR analysis, dried commercial samples were obtained from PT Perkebunan Nusantara (Nusantara Plantation XIII) in Jember, Indonesia. Samples were spontaneously fermented for three days on-site in January-February 2018. The dried cocoa bean from commercial samples were stored in $4 \pm 3$ ${ }^{\circ} \mathrm{C}$ before further analysis.

\subsection{Total plate count and total yeast-mold}

Total Plate Count (TPC) and Total Yeast-Mold (TYM) was performed as described by Fardiaz (1993). Nutrient Agar (NA) (Accumedia, USA), De Mann Rogosa Sharpe Agar (Himedia, India), and Dichloran Rose-bengal Chloramphenicol Agar (DRBCA) (Oxoid, USA) was used for TPC, Lactic acid bacteria (LAB) count, and TYM, respectively. The sample weighed about $25 \mathrm{~g}$ in $0.86 \% \mathrm{Nacl}$ solution. As many as $0.1 \mathrm{~mL}$ that had been aseptically poured into a petri dish andSprate plate. For TPC and LAB observations, the samples were incubated in the incubator in a reversed position at $37^{\circ} \mathrm{C}$ for 24 hours. For TYM, the samples were incubated at $\left(27 \pm 3^{\circ} \mathrm{C}\right)$ for $72-96$ hours. Calculations according to SPC (Standard Plate Count) number of colonies range from 25 to $250 \mathrm{CFU} / \mathrm{mL}$, taking into account the dilution factor. The non-LAB population calculation was performed by subtracting the $\log$ of the total bacterial population obtained from the NA medium with the log of the LAB population of the MRSA medium.

\section{$2.3 \mathrm{pH}$}

The degree of acidity was measured using the Sudarmadji et al. (2007) method. About $50 \mathrm{~mL}$ of sample product was placed into a small jar, and the $\mathrm{pH}$ was measured in duplicate for each product. Before analysis, the $\mathrm{pH}$ meter was checked and calibrated by comparing the values with buffer $\mathrm{pH} 4$ and 9 .

\subsection{Total phenol}

The total phenol analysis was carried out based on The previous methods by (Mu'nisa et al., 2012; Nurhayati et al., 2012). Cocoa bean powder was weighed at $0.3 \mathrm{~g}$, and then dissolved to $10 \mathrm{~mL}$ in absolute ethanol (SmartLab, Indonesia): aqua distillate (1: 1). The extract solution was taken as much as $0.2 \mathrm{~mL}$. To the solution, $15.8 \mathrm{~mL}$ aqua distillate was added, followed by the addition of $1 \mathrm{~mL}$ Folin-Ciocalteu reagent (SigmaAldrich, USA) $50 \%(\mathrm{v} / \mathrm{v})$ in ethanol. The mixture was left to stand for $8 \pm 2$ mins, then $3 \mathrm{~mL}$ of $\mathrm{Na}_{2} \mathrm{CO}_{3} 5 \%$ (w/ v) (Sigma-Aldrich, USA) was added. The solution was left to stand for $2 \mathrm{hrs}$ in The dark at $28 \pm 2^{\circ} \mathrm{C}$ room temperature $\left(28 \pm 2^{\circ} \mathrm{C}\right)$, then the absorbance was measured at $725 \mathrm{~nm}$ (Eppendorf BioSpectrometer ${ }^{\circledR}$, Germany). Quantification of total phenol was carried out using the Gallic acid (Sigma-Aldrich, USA) standard curve, which had been prepared in the same way. Total phenol was expressed in $\mathrm{mg}$ equivalent Gallic acid per kg dry weight.

\subsection{Total theobromine}

The total measurement of theobromine (TB) by UV spectrophotometry was done according to the method by Li et al. (1991). lead II solution was made by mixing 15 $\mathrm{g}$ of $\mathrm{Pb}$ (II) acetate (Merck, USA) with $150 \mathrm{~mL}$ of water in a $250 \mathrm{~mL}$ flask, and then the solution was heated while stirring until the color of the solution turned white. The control used was $0.1 \mathrm{~g}$ TB (Sigma-Aldrich, USA). Cocoa bean powder was weight at $0.1 \mathrm{~g}$ and transferred into a $150 \mathrm{~mL}$ glass, and $96 \mathrm{~mL}$ of distilled water was added. The solution was heated $\left(70 \pm 10^{\circ} \mathrm{C}\right)$ for 5 mins while stirring. About $4 \mathrm{~mL}$ of lead II solution was added and mixed. Distilled water was added until the volume of the solution became $100 \mathrm{~mL}$. To the mixture, $1 \mathrm{~g}$ of $\mathrm{NaHCO}_{3}$ (Sigma-Aldrich, USA) was added. Then, the precipitate was filtered with filter paper three times until the solution became transparent. The filtrate $(50 \mathrm{~mL})$ was removed, and about $5.5 \mathrm{~mL}$ of $1 \mathrm{M} \mathrm{NaOH}$ (SigmaAldrich, USA) was added to produce $\mathrm{pH}$ 10.5. Then, the filtrate was extracted with chloroform (Fulltime, China) in five repetitions, each of which was added $25,20,15$, 15 and $10 \mathrm{~mL}$ of chloroform. In each repetition, the mixture was shaken for $1 \mathrm{~min}$ and stand for about 5 mins. Chloroform extract was combined into a volumetric flask and added with chloroform so that it reached a volume of $100 \mathrm{~mL}$. About $10 \mathrm{~mL}$ of extract in 
chloroform was added with $40 \mathrm{~mL}$ of aqua distillate and $0.55 \mathrm{~mL}$ of $10 \% \mathrm{HCl}$. The determination of theobromine spectrophotometry was carried out by transferring $1 \mathrm{~mL}$ of chloroform extract into the cuvette and measured the absorbance at a wavelength of $302 \mathrm{~nm}$. The results obtained were then plotted in the standard curve of TB (Sigma-Aldrich, USA).

\subsection{Antioxidant activity}

Total antioxidants were performed by a spectrophotometric method using 2, 2-diphenyl-1picrylhydrazyl (DPPH) (Sigma-Aldrich, USA) reduction principle (Farhan et al., 2012). A total of $1 \mathrm{~mL}$ of diluted extract in ethanol (Kimia Farma, Indonesia) was added to $1 \mathrm{~mL}$ DPPH (prepared at $0.15 \mathrm{mM}$ in ethanol), and at the same time, a control consisting of $1 \mathrm{~mL}$ of DPPH with $1 \mathrm{~mL}$ of ethanol was prepared. The reaction mixture was vortexed and then incubated in the dark at room temperature for 30 mins. The absorbance was measured at $519 \pm 2 \mathrm{~nm}$ (Genesys 20, Thermo-Fischer, USA). Vitamin C (Sigma Aldrich, USA) was used as a positive control, and ethanol was used as the subtract. The ability to inhibit DPPH reduction of the extract was calculated by comparing the absorbance of the reduced control of sample absorbance divided by the absorbance of the control. The total antioxidant value was then plotted in a linear regression equation: [antioxidant potential] $=\mathrm{a}$ [ingredient in ppm] $+\mathrm{b}$ to obtain its $\mathrm{IC}_{50}$ value.

\subsection{FTIR Analysis}

The samples were in the form of powder. All samples then analyzed to obtain infrared (IR) spectrogram with Shimadzu FTIR-8400S (Michelson interferometer, single-ray optical system, a globular infrared ceramic source with an $\mathrm{S} / \mathrm{N}$ ratio of 20000: 1, Happ-Genzel Apodization, and 10x readings at the resolution of 4.0).

\section{Results and discussion}

\subsection{Microbial population, $\mathrm{pH}$, and total acids}

Microbial populations, $\mathrm{pH}$, and total titrated acid from fermented cocoa using starter cultures were compared with the same parameters of spontaneously fermented cocoa (Table 1). On the 4th day of fermentation, spontaneously fermented cocoa had a TPC value of $8.11 \pm 0.83 \log \mathrm{CFU} / \mathrm{mL}$, a total $\mathrm{LAB}$ of $5.87 \pm 0.91 \log \mathrm{CFU} / \mathrm{mL}$, and a total $\mathrm{YM}$ of $4.22 \pm 0.65 \log$ $\mathrm{CFU} / \mathrm{mL}$. In general, there was no significant difference in total microbes between spontaneously fermented cocoa and fermented cocoa using a starter. Based on previous research (Da Veiga-Moreira et al., 2013), the difference between fermented cocoa with a starter and without a starter in terms of population size generally did not experience a difference ( $p>0.05)$, except for the use of a mixed culture starter. In this case, the Total YeastMold (TYM), fermentation by mixed culture starter inoculation was higher when compared to the total YM in spontaneous fermentation. Mixing of mixed culture starters was thought to cause a decrease in the activity of microorganisms that inhibit YM growth, which was indicated by the final $\mathrm{pH}$ of the product being significantly different. Nutritional use competition is thought to be the cause that the final $\mathrm{pH}$ of fermented cocoa with various inoculums becomes different (Lee et al., 2019).

The cocoa fermentation process involves a microbial complex that has a successful role in shutting down the viability of the cocoa germ, reducing bitter taste by reducing polyphenols and flavonoids, and reducing the final pH (Da Veiga-Moreira et al., 2013). In terms of the use of a starter, the benefit is a more consistent end result with an emphasis on certain fermentation stages. The intended outcomes include stabilizing the process of turning pulp into alcohol, forming the aroma of vinegar and lactic acid, or reducing the $\mathrm{pH}$ rapidly to inhibit the growth of mycotoxin-producing molds (De Melo-Pereira et al., 2012).

Two parameters commonly used to monitor the ongoing process of cocoa fermentation are $\mathrm{pH}$ and temperature of fermentation (Lefeber, Gobert and Vrancken et al., 2011). In this study, the fermentation temperature was not reported, but somewhat dependent on the $\mathrm{pH}$. Total acid can be used to confirm changes in $\mathrm{pH}$ during the cocoa fermentation process. In addition to vinegar, succinic acid is the dominant source of $\mathrm{pH}$ reduction in cocoa fermentation, with the help or without the help of a starter (De Melo-Pereira et al., 2012). In general, the final $\mathrm{pH}$ and total acid observed at the end of

Table 1. Microbial populations, $\mathrm{pH}$, and total acids of fermented Samarinda cocoa bean

\begin{tabular}{lccccc}
\hline Type of Cocoa Bean Fermentation & $\begin{array}{c}\text { TPC } \\
(\log \text { CFU/mL) }\end{array}$ & $\begin{array}{c}\text { LAB } \\
(\log \text { CFU/mL) }\end{array}$ & $\begin{array}{c}\text { YM } \\
(\log \text { CFU/mL) }\end{array}$ & pH & $\begin{array}{c}\text { Total acids } \\
(\%)\end{array}$ \\
\hline Spontaneous & $8.11 \pm 0.83$ & $5.87 \pm 0.91$ & $4.22 \pm 0.65$ & $4.33 \pm 0.03$ & $0.09 \pm 0.01$ \\
S. cerevisiae induced & $7.97 \pm 0.85$ & $6.12 \pm 0.68$ & $5.14 \pm 0.77$ & $4.30 \pm 0.28$ & $0.11 \pm 0.01$ \\
A. aceti induced & $7.89 \pm 0.91$ & $6.02 \pm 0.88$ & $5.22 \pm 0.83$ & $4.38 \pm 0.00$ & $0.10 \pm 0.02$ \\
Mixed culture induced & $7.96 \pm 0.81$ & $5.58 \pm 0.85$ & $5.94 \pm 0.81 *$ & $4.98 \pm 0.00^{*}$ & $0.08 \pm 0.01$ \\
\hline
\end{tabular}

$*$ indicates significant different $(\mathrm{p}<0.05)$ 
the fermentation process for four days did not experience a significant difference $(p>0.05)$, except for mixed culture fermentation. The $\mathrm{pH}$ value of cocoa fermentation products with the help of mixed culture inoculum was significantly different $(p<0.05)$ compared to the final $\mathrm{pH}$ on spontaneous fermentation of cocoa.

In many cocoa fermentation operations in the world, spontaneous fermentation is the first choice with a note that the stages of fruit shell opening, removal of fruit pulp, and laying on a fermentation container are done hygienically (Papalexandratou et al., 2011). This means that the use of a starter, in general, does not significantly affect the etiology of the decrease in $\mathrm{pH}$ and the increase in total acid during the cocoa fermentation process. Except, inoculum conditions do not quickly enough converting sugar to alcohol and alcohol to vinegar (Lefeber, Janssens and Moens et al., 2011).

\subsection{Total phenol, theobromine, and antioxidant capacity}

Table 2 explains the changes in total phenols, theobromine, and antioxidant capacity of cocoa fermentation using several starters compared to spontaneously fermented cocoa. The antioxidant capacity of cocoa fermented by these four methods was significantly different $(\mathrm{p}<0.05)$. However, when viewed from its antioxidant source, cocoa fermented with $S$. cerevisiae inoculum had the highest total phenol compared with the same compound content in other fermented cocoa. The total phenols in cocoa fermented with $A$. aceti inoculum and mixed culture were lower when compared to the other two fermentation methods. It is notable that the phenolic content was more affected by the presence of the Acetobacter inoculum than the $S$. cerevisiae inoculum (Lee et al., 2019). In another study, spontaneous fermentation produced a better phenolic profile and total antioxidant compared to fermentation with the help of $S$. cerevisiae starter, because of continuous fermentation that involved many microbes (Batista et al., 2016).

The total theobromine in spontaneously fermented and mixed culture cocoa did not differ significantly $(\mathrm{p}>0.05)$. The lowest total theobromine was obtained in fermented cocoa using S. cerevisiae inoculum. This indicates the theobromine degradation process occurs more at the alcoholic fermentation stage (Sandhya et al.,
2016). One suspected cause is the presence of fungi that can degrade theobromine as occurs in cocoa husk fermentation (Adamafio et al., 2012).

There was generally no strong correlation between the total polyphenols and antioxidant capacity (Table 2). Pearson correlation test (data not shown) showed no relationship between the total phenolic component in the fermented cocoa from various starters and their antioxidant capacity. Then, there was an indication that a group of methylxanthine compounds such as theobromine and caffeine could be considered as sources of antioxidants. However, the radical scavenging ability of methylxanthine compounds has not been proven in major reports (Sroka et al., 2015; Petrucci et al., 2018). Although Table 2 indicates that there was a possible relationship between total theobromine and antioxidant capacity, previous studies had focused only on the antioxidant capacity of cocoa sourced from polyphenol contents (Cádiz-Gurrea et al., 2014; Todorovic et al., 2015). Species of polyphenols determines the antioxidant activity strength of cocoa (Carrillo et al., 2014), so the quantification of each polyphenol species from fermented cocoa with various starters needs to be conducted in the future.

\subsection{FTIR analysis of fully fermented cocoa bean}

Figure 1 illustrates the FTIR spectrum of cocoa beans that had been fermented spontaneously or with the help of $A$. aceti and $S$. cerevisiae inoculums. For comparison, the results of this fermentation were compared with cocoa beans obtained from a commercial factory owned by PTPN XIII. In general, all fermented cocoa beans had almost the same FTIR spectrum in the range of wavenumbers from 400 to $4000 \mathrm{~cm}^{-1}$. Based on Figure 1, fermentation caused a change in $\% \mathrm{~T}$ of the FTIR spectrum, especially in the wavenumber between 3600 and $3800 \mathrm{~cm}^{-1}$ (O-H stretching), $1600-1700 \mathrm{~cm}^{-1}$ (C $=\mathrm{O}$ ), and 400-950 $\mathrm{cm}^{-1}$. In addition to carbonyl and O$\mathrm{H}$, the functional group markers of 120 hours fermented cocoa butter shell consist of $\mathrm{C}-\mathrm{H}$ aldehyde, $\mathrm{C}-\mathrm{H}, \mathrm{CH}_{2}$, $\mathrm{CH}_{3}, \mathrm{C}-\mathrm{O}$ (ester), and C-O-C (Utami et al., 2016).

The lactic acid bacteria fermentation has a zone of identification or marker of proteins, carbohydrates, nucleic acids, and bacterial DNA detected in the wavenumber between 900 and $1300 \mathrm{~cm}^{-1}$ (Vodnar et al.,

Table 2. Total phenol, theobromine, and antioxidant capacity of fermented Samarinda cocoa bean

\begin{tabular}{lccc}
\hline \multicolumn{1}{c}{ Types of fermentation } & $\begin{array}{c}\text { Total phenol } \\
(\mathrm{ppm} \text { GAE) }\end{array}$ & $\begin{array}{c}\text { Antioxidant Capacity } \\
\mathrm{IC}_{50} \text { against DPPH }(\mathrm{ppm})\end{array}$ & $\begin{array}{c}\text { Total theobromine } \\
(\mathrm{ppm})\end{array}$ \\
\hline Spontaneous & $3,027.6 \pm 110.5^{\mathrm{a}}$ & $461.6 \pm 2.0^{\mathrm{a}}$ & $162.3 \pm 22.6^{\mathrm{a}}$ \\
S. cerevisiae induced & $3,183.8 \pm 47.3^{\mathrm{b}}$ & $521.7 \pm 3.8^{\mathrm{b}}$ & $53.3 \pm 13.8^{\mathrm{b}}$ \\
A. aceti induced & $2,173.9 \pm 102.6^{\mathrm{c}}$ & $892.8 \pm 2.3^{\mathrm{c}}$ & $93.2 \pm 2.5^{\mathrm{c}}$ \\
Mixed culture induced & $2,134.8 \pm 31.6^{\mathrm{c}}$ & $424.9 \pm 3.3^{\mathrm{d}}$ & $154.4 \pm 1.3^{\mathrm{a}}$ \\
\hline
\end{tabular}

Values with the same superscript indicate no significant difference $(\mathrm{p}>0.05)$. 

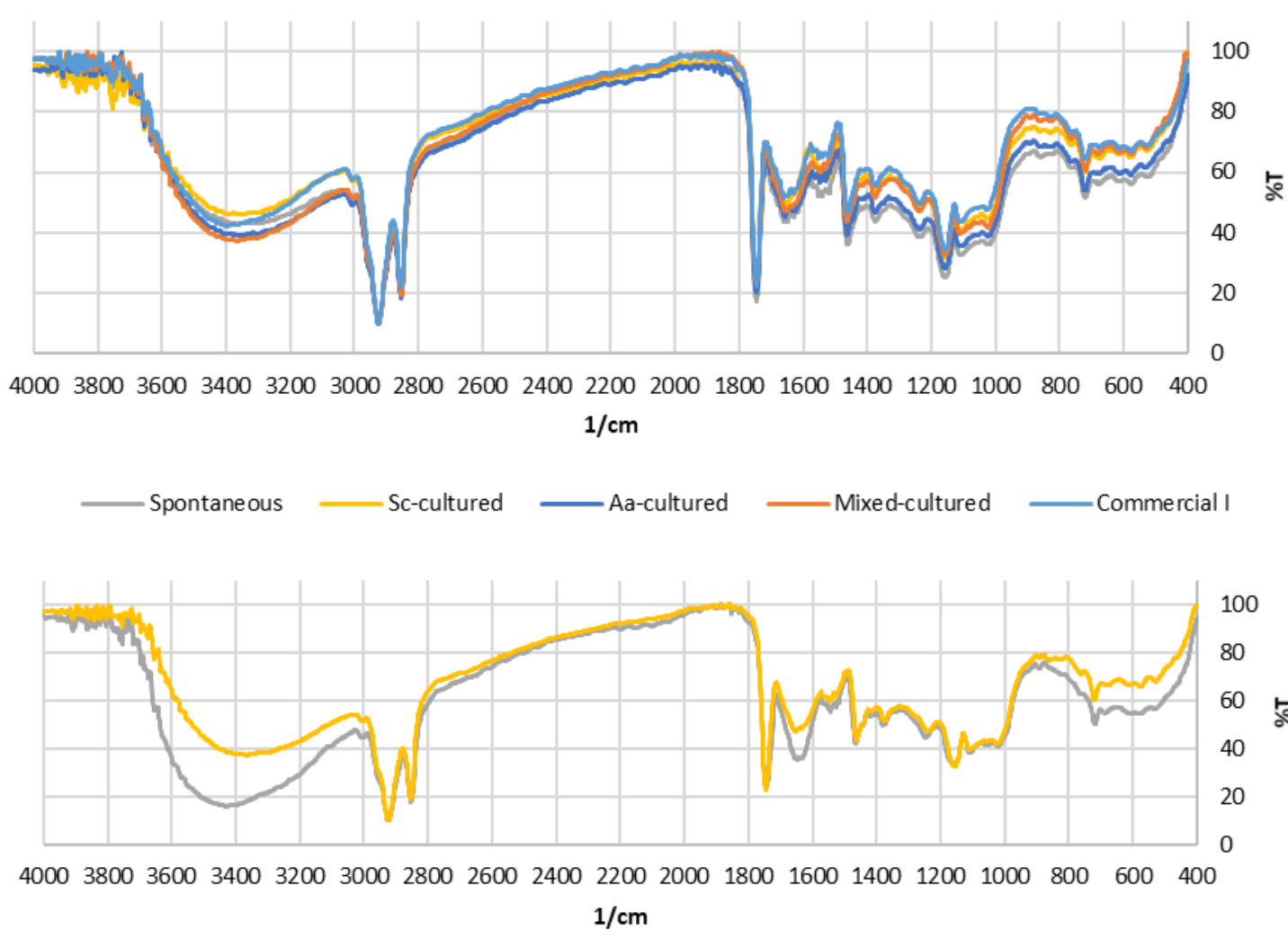

Mixed Culture Day-1

- Mixed Culture Day-4

Figure 1. (a) Full range FTIR analysis of fermented Samarinda cocoa bean compared to commercial I (b) Full range FTIR analysis of partly and fully fermented Samarinda cocoa bean.

2010). In other studies, fermented cocoa with various inoculums has a slightly different FTIR profile, mainly on antioxidant components (Batista et al., 2016). Fermentation causes changes in $\mathrm{C}=\mathrm{O}$ stretching vibrations detected in the wavenumber range 1300-1900 $\mathrm{cm}^{-1}$. Changes in moisture and water activity $(\mathrm{O}-\mathrm{H}$ stretching) as a result of bacterial fermentation were detected in the wavenumber range $3100-3700 \mathrm{~cm}^{-1}$, as seen in variations of cellulose products from bacterial fermentation (Halib et al., 2012). The FTIR spectra of fermented products has unique characteristics, depending on the dominant microbes present at the time of the fermentation (Shalin et al., 2014).

\subsection{FTIR analysis of fully fermented cocoa bean against theobromine identification regiment}

One effort to see changes due to fermentation is to compare the FTIR spectrum of fermented cocoa with theobromine standard, especially in the wavenumber FTIR identification zone from 600 to $1500 \mathrm{~cm}^{-1}$ (Figure 2 and Table 3). the FTIR spectrum of the theobromine standard was measured with the same tool to avoid too much peak shifting. The shift is around 5\% due to differences in the complexity of biological tissue, methods, tools, and binding media (Movasaghi et al., 2008). FTIR spectrum reading for theobromine standard produced peak identification on wave numbers 1485 ,
$1456,1425,1412,1366,1335,1294,1225,1173,1138$, $1070,939,889,783,750,731,683$ and $615 \mathrm{~cm}^{-1}$. After comparing with the database and composition of theobromine deduction, the FTIR peaks occurred because of vibrations from the covalent bonds of $\mathrm{C}=\mathrm{O}, \mathrm{N}$ $-\mathrm{H}, \mathrm{C}=\mathrm{N}$, and $\mathrm{C}-\mathrm{N}-\mathrm{C}$ (Figure 2). The calculations in Table 3 attempted to quantify how much \%A difference from each fermented cocoa with a different inoculum when compared to theobromine standards. Spontaneously fermented cocoa had the highest absorbance difference in theobromine FTIR identification peaks.

Meanwhile, cocoa fermented by mixed culture ( $A$. aceti and $S$. cerevisiae) and had the lowest absorbance difference in theobromine FTIR identification peaks. This difference was caused by differences in the inoculum used as induction of the fermentation process as previously described (Vodner et al., 2010; Halib et al., 2012; Shalin et al., 2014). Based on the FTIR spectrum in the theobromine identification zone, fermented cocoa with a mixture of $A$. aceti and $\mathrm{S}$. cerevisiae had the closest quality to commercial cocoa samples.

\subsection{FTIR analysis of fully fermented cocoa bean against caffeine identification regiment}

Not only does cocoa contain theobromine, but it also contains significant amounts of caffeine (Batista et al., 


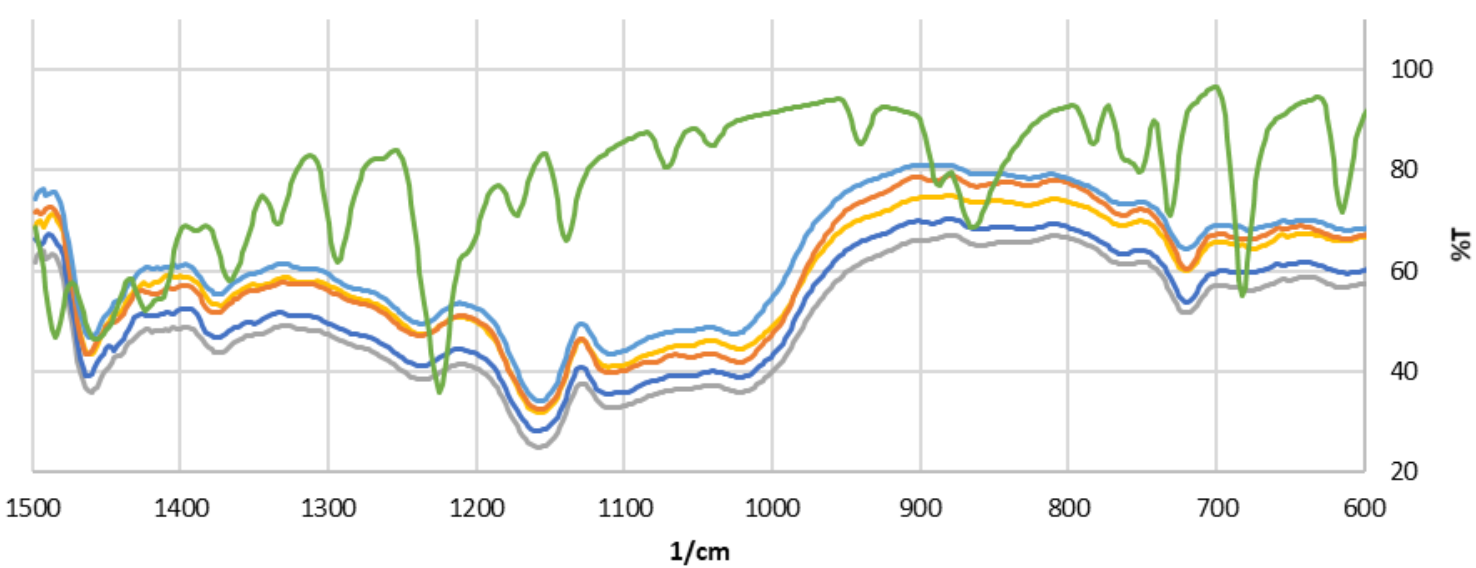

— Spontaneous — Sc-cultured — Aa-cultured —— Mixed-cultured —C Commercial I — Theobromine

Figure 2. Theobromine IR identification regiment of fermented Samarinda cocoa bean compared to commercial I

Table 3. Peak wavelengths of theobromine IR identification regiment of fermented Samarinda cocoa bean

\begin{tabular}{cccccc}
\hline \multirow{2}{*}{ Wave Number $(1 / \mathrm{cm})$} & \multicolumn{5}{c}{ \%A vs. Theobromine } \\
\cline { 2 - 6 } & Spontaneous & S. cerevisiae -induced & A. aceti -induced & Mixed culture-induced & Commercial I \\
\hline 1485 & -16.2 & -24.12 & -19.25 & -25.16 & -28.82 \\
1456 & 9.56 & 1.48 & 4.6 & 0.5 & -1.2 \\
1425 & 4.37 & -5.18 & 1 & -3.68 & -8.07 \\
1412 & 6.49 & -3.98 & 3.16 & -1.33 & -5.9 \\
1366 & 12.91 & 3.24 & 9.79 & 4.35 & 1 \\
1335 & 20.55 & 11.21 & 17.76 & 12.04 & 8.2 \\
1294 & 15.3 & 5.52 & 12.95 & 6.53 & 3.66 \\
1225 & -3.87 & -13.26 & -6.9 & -13.11 & -15.66 \\
1173 & 41.89 & 34.11 & 38.75 & 33.7 & 30.93 \\
1138 & 33.19 & 25.47 & 30.14 & 24.98 & 21.83 \\
1070 & 44.46 & 35.97 & 41.62 & 37.6 & 32.86 \\
939 & 23.69 & 15.02 & 19.5 & 11.58 & 8.02 \\
889 & 10.7 & 2.55 & 7.59 & -0.74 & -3.7 \\
783 & 20.55 & 13.11 & 18.57 & 10.38 & 8.7 \\
750 & 18.1 & 10.06 & 15.85 & 7.7 & 6.22 \\
731 & 15.48 & 6.98 & 12.42 & 5.04 & 3.29 \\
683 & -1.52 & -10.36 & -4.64 & -11.22 & -13.6 \\
615 & 14.92 & 5.78 & 12.03 & 5.27 & 3.51 \\
\hline
\end{tabular}

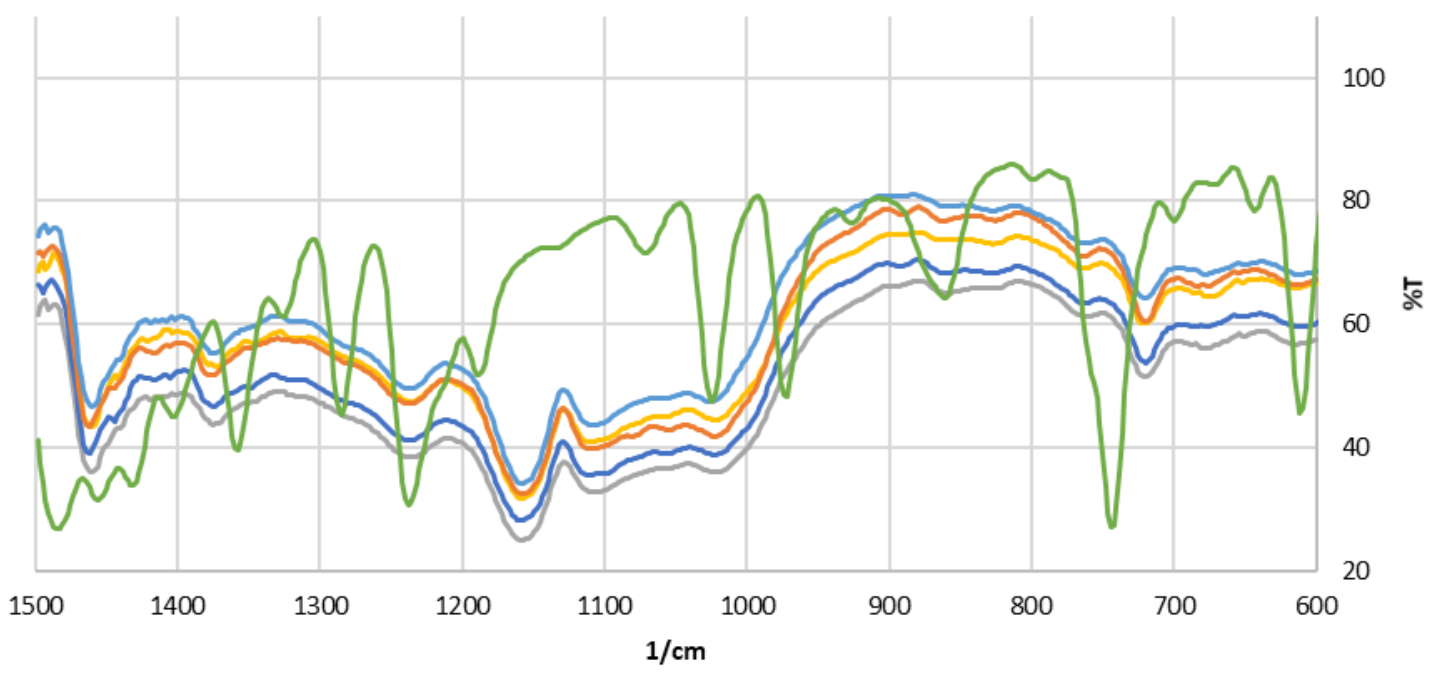

$\longrightarrow$ Spontaneous $\longrightarrow$ Sc-cultured $\longrightarrow$ Aa-cultured $\longrightarrow$ Mixed-cultured $\longrightarrow$ Commercial I $\longrightarrow$ Caffeine

Figure 3. Caffeine IR identification regiment of fermented Samarinda cocoa bean compared to commercial I 
Table 4. Peak wavelengths of caffeine IR identification regiment of fermented Samarinda cocoa bean

\begin{tabular}{cccccc}
\hline \multirow{2}{*}{ Wave Number (1/cm) } & \multicolumn{5}{c}{ \%A vs. Caffeine } \\
\cline { 2 - 6 } & Spontaneous & S. cerevisiae -induced & A. aceti -induced & Mixed culture-induced & Commercial I \\
\hline 1483 & -14.90 & -22.44 & -17.69 & -23.73 & -27.59 \\
1454 & 8.43 & 0.25 & 3.98 & -0.10 & -2.44 \\
1431 & 10.76 & 1.18 & 6.49 & 1.76 & -1.29 \\
1402 & 17.83 & 7.44 & 14.23 & 9.47 & 5.47 \\
1358 & 17.00 & 7.27 & 14.11 & 8.17 & 4.93 \\
1325 & 28.44 & 19.20 & 26.35 & 19.98 & 16.38 \\
1285 & 26.85 & 17.29 & 24.56 & 18.21 & 15.53 \\
1236 & 17.09 & 8.06 & 35 & 5.98 \\
1188 & 38.98 & 30.15 & 41.82 & 29.48 & 26.84 \\
1072 & 44.61 & 36.20 & 50.63 & 37.90 & 33.01 \\
1026 & 53.57 & 44.99 & 36.32 & 29.81 & 42.18 \\
972 & 40.74 & 31.40 & 25.18 & 17.11 & 24.06 \\
928 & 29.11 & 20.81 & 0.81 & -7.73 & 13.64 \\
862 & 3.86 & -4.59 & 24.00 & 15.19 & -10.16 \\
800 & 26.11 & 18.93 & 26.64 & 18.72 & 14.31 \\
743 & 29.04 & 20.96 & 35.99 & 28.49 & 17.10 \\
698 & 38.72 & 30.12 & 31.79 & 24.58 & 26.75 \\
642 & 34.70 & 26.11 & 16.10 & 9.23 & 23.37 \\
611 & 18.77 & 9.61 & & & 7.51 \\
\hline
\end{tabular}

2016). Changes that occur in fermented cocoa to caffeine standards need to be observed, especially in the FTIR identification zone in the range of wavenumbers from 600 to $1500 \mathrm{~cm}^{-1}$ (Figure 3 and Table 4). Caffeine identification peaks were found on wavenumber of 1483, $1454,1431,1402,1358,1325,1285,1236,1188,1072$, $1026,972,928,862,800,743,698,642$, and $611 \mathrm{~cm}^{-1}$ (Table 4). Based on the structure of caffeine, the identification peaks can be assumed to be originated from vibrations of covalent bonds consisting of $=\mathrm{C}=\mathrm{N}$ (conjugated, cyclic), $=\mathrm{N}-\mathrm{N}=\mathrm{O},-\mathrm{CH}_{3},=\mathrm{CH}_{2}, \mathrm{C}-\mathrm{N}=\mathrm{O}$, $\mathrm{OH},=\mathrm{C}-\mathrm{O}-\mathrm{C}-,-\mathrm{CH}=\mathrm{CH}_{2}$, three neighboring aromatic $\mathrm{C}$ $\mathrm{H}$, and ethylene (Rahmadi et al., 2019).

As is the case with the theobromine functional groups, the absorbance value of the FTIR spectrum in the caffeine identification zone was compared with the absorbance of the FTIR spectra in fermented and commercial cocoa (Table 4). Industrial cocoa had the most absorbance difference in the value of caffeine when compared to fermented cocoa used in this study. The use of $A$. aceti and $S$. cerevisiae mixed culture in the fermentation process produces cocoa with the difference of caffeine absorbance, which was the closest to commercial cocoa. However, quantification of caffeine levels in fermented cocoa with the help of an induction inoculum needs to be further confirmed.

\section{Conclusion}

There was no difference in the total population of bacteria, LAB, and yeast and mold in all fermented cocoa samples. Mixed culture fermented cocoa has a slightly lower final $\mathrm{pH}$ compared to other cocoa samples. Spontaneously fermented cocoa and mixed culture have the highest levels of theobromine compared to other fermentation methods. Fermented cocoa with $S$. cerevisiae inoculum has the highest total phenol compared to the same compound content in other fermented cocoa. Better antioxidant capacity was obtained from fermented cocoa with a mixed culture. Based on FTIR analysis in the theobromine and caffeine identification zones, fermented cocoa with a mixture of $A$. aceti and $S$. cerevisiae had the closest quality to commercial cocoa samples.

\section{Conflict of Interest}

The authors declare no conflict of interest.

\section{Acknowledgments}

Authors thank Ministry of Research, Technology, and Higher Education for partial funding in the scheme of University of Mulawarman Islamic Development Bank Student Mobility Program.

\section{References}

Adamafio, N.A., Kolawole, O.M. and Oduro-Mensah, D. (2012). Theobromine-degrading potential of yeast strain isolated from tomato (Lycopersicon esculentum) fruit. International Journal of Biological Chemistry, 6(4), 103-112. https:// doi.org/10.3923/ijbc.2012.103.112

Altemimi, A., Lakhssassi, N., Baharlouei, A., Watson, D.G. and Lightfoot, D.A. (2017) Phytochemicals: Extraction, Isolation, and Identification of Bioactive Compounds from Plant Extracts. Plants, 6(4), 42. https://doi.org/10.3390/plants6040042 
Batista, N.N., de Andrade, D.P., Ramos, C.L., Dias, D.R. and Schwan, R.F. (2016). Antioxidant capacity of cocoa beans and chocolate assessed by FTIR. Food Research International, 90, 313-319. https:// doi.org/10.1016/j.foodres.2016.10.028

Cádiz-Gurrea, M., Lozano-Sanchez, J., ContrerasGámez, M., Legeai-Mallet, L., Fernández-Arroyo, S. and Segura-Carretero, A. (2014). Isolation, comprehensive characterization, and antioxidant activities of Theobroma cocoa extract. Journal of Functional Foods, 10, 485-498. https:// doi.org/10.1016/j.jff.2014.07.016

Carrillo, L.C., Londoño-Londoño, J. and Gil, A. (2014). Comparison of polyphenol, methylxanthines and antioxidant activity in Theobroma cocoa beans from different cocoa-growing areas in Colombia. Food Research International, 60, 273-280. https:// doi.org/10.1016/j.foodres.2013.06.019

Cempaka, L., Aliwarga, L., Purwo, S. and Kresnowati, M.T.A.P. (2014). Dynamics of Cocoa Bean Pulp Degradation during Cocoa Bean Fermentation: Effects of Yeast Starter Culture Addition. Journal of Mathematical and Fundamental Sciences, 46(1), 1425. https://doi.org/10.5614/ j.math.fund.sci.2014.46.1.2

Da Veiga-Moreira, I.M., Miguel, M.G.D.C.P., Duarte, W.F., Dias, D.R. and Schwan, R.F. (2013). Microbial succession and the dynamics of metabolites and sugars during the fermentation of three different cocoa (Theobroma cocoa L.) hybrids. Food Research International, 54(1), 9-17. https:// doi.org/10.1016/j.foodres.2013.06.001

De Melo-Pereira, G.V., Miguel, M.G.D.C.P., Ramos, C.L. and Schwan, R.F. (2012). Microbiological and physicochemical characterization of small-scale cocoa fermentations and screening of yeast and bacterial strains to develop a defined starter culture. Applied and Environmental Microbiology, 78(15), 5395-5405. https://doi.org/10.1128/AEM.01144-12

De Vuyst, L. and Stefan, W. (2016). The cocoa bean fermentation process: from ecosystem analysis to starter culture development. Journal of Applied Microbiology, 121(1), 5-17. https://doi.org/10.1111/ jam. 13045

Fardiaz, S. (1993). Mikrobiologi Pangan, p. 1-46. Bogor: Institut Pertanian Bogor. [In Bahasa Indonesia].

Farhan, H., Rammal, H., Hijazi, A., Hamad, H., Daher, A., Reda, M. and Badran, B. (2012). In vitro antioxidant activity of ethanolic and aqueous extracts from crude Malva parviflora L. Grown in Lebanon. Asian Journal of Pharmaceutical and Clinical Research, 5(3), 234-238.
Halib, N., Amin, M.C.I.M. and Ahmad, A. (2012). Physicochemical Properties and Characterization of Nata de Coco from Local Food Industries as a Source of Cellulose. Sains Malaysiana, 41(2), 205211.

Koch, C., Posch, A.E., Goicoechea, H.C., Herwig, C. and Lendl B. (2013). Multi-analyte quantification in bioprocesses by Fourier-transform-infrared spectroscopy by partial least squares regression and multivariate curve resolution. Analytica Chimica Acta, 807, 103-110. https://doi.org/10.1016/ j.aca.2013.10.042

Lee, A. H., Neilson, A.P., O'Keefe, S.F., Ogeje, J.A., Huang, H., Ponder, M., Chu, H.S.S, Jin, Q., Pilot, G. and Stewart, A.C. (2019). A laboratory-scale model cocoa fermentation using dried, unfermented beans and artificial pulp can simulate the microbial and chemical changes of on-farm cocoa fermentation. European Food Research and Technology, 245, 511 -519. https://doi.org/10.1007/s00217-018-3171-8

Lefeber, T., Gobert, W., Vrancken, G., Camu, N. and De Vuyst, L. (2011). Dynamics and species diversity of communities of lactic acid bacteria and acetic acid bacteria during spontaneous cocoa bean fermentation in vessels. Food Microbiology, 28(3), 457-464. https://doi.org/10.1016/j.fm.2010.10.010.

Lefeber, T., Janssens, M., Moens, F., Gobert, W. and De Vuyst, L. (2011). Interesting starter culture strains for controlled cocoa bean fermentation revealed by simulated cocoa pulp fermentations of cocoa-specific lactic acid bacteria Applied and Environmental Microbiology, 77(18), 6694-6698. https:// doi.org/10.1128/AEM.00594-11

Li, S., Varadarajan, G.S. and Hartland, S. (1991). Solubilities of theobromine and caffeine in supercritical carbon dioxide: correlation with density -based models. Fluid Phase Equilibria, 68, 263-280. https://doi.org/10.1016/0378-3812(91)85023-N

Meersman, E., Steensels, J., Paulus, T., Struyf, N., Saels, V., Mathawan, M., Koffi, J., Vrancken, G. and Verstrepen, K.J. (2015). Breeding Strategy to Generate Robust Yeast Starter Cultures for Cocoa Pulp Fermentations. Applied and Environmental Microbiology, 81(18), 6166-6176. https:// doi.org/10.1128/AEM.00133-15

Meersman, E., Steensels, J., Struyf, N., Paulus, T., Saels, V., Mathawan, M., Allegaert, L. and Vrancken, G., Verstrepen, K.J. (2016). Tuning Chocolate Flavor through Development of Thermotolerant Saccharomyces cerevisiae Starter Cultures with Increased Acetate Ester Production. Applied and Environmental Microbiology, 82(2), 732-746. https://doi.org/10.1128/AEM.02556-15 
Movasaghi, Z., Rehman, S. and Rehman, I.U (2008). Fourier Transform Infrared (FTIR) Spectroscopy of Biological Tissues. Applied Spectroscopy Reviews, 43(2), 134-179. https:// doi.org/10.1080/05704920701829043

Mu'nisa, A., Wresdiyati, T., Kusumorini, N. and Manalu. W. (2012). Antioxidant activity of clove leaf extract. Jurnal Veteriner, 13(3), 272-277.

Nurhayati, Siadi, K. and Harjono. (2012). Effect of sodium benzoate concentration and storage duration on total phenolic content of tomato paste. Indonesian Journal of Chemistry Science, 1(2), 158-163.

Papalexandratou, Z., Camu, N., Falony, G. and De Vuyst, L. (2011). Comparison of the bacterial species diversity of spontaneous cocoa bean fermentations carried out at selected farms in Ivory Coast and Brazil. Food Microbiology, 28(5), 964973. https://doi.org/10.1016/j.fm.2011.01.010

Petrucci, R., Zollo, G., Curulli, A. and Marrosu, G. (2018). A new insight into the oxidative mechanism of caffeine and related methylxanthines in aprotic medium: May caffeine be really considered as an antioxidant? Biochimica et Biophysica Acta (BBA)General Subjects, 1862(8), 1781-1789. https:// doi.org/10.1016/j.bbagen.2018.05.011

Rahmadi, A. and Fleet, G.H. (2008). The occurrence of mycotoxigenic moulds in cocoa beans from Indonesia and Queensland, Australia presented at the Proceeding of International Seminar on Food Science, p. 1-18. Semarang: Catholic Universitas Soegija Pranata.

Rahmadi, A., Istiqomah, M. and Emmawati, A. (2019). Observation of Bitterness Reducing Ability of Melastomataceae Leaf Extracts on Caffeine and Coffee Powder. Ekoloji, 28(108), 2705-2714.

Sandhya, M.V.S., Yallappa, B.S., Varadaraj, M.C., Puranaik, J., Rao, L.J., Janardhan, P. and Murthy, P.S. (2016). Inoculum of the starter consortia and interactive metabolic process in enhancing quality of cocoa bean (Theobroma cocoa) fermentation. LWTFood Science and Technology, 65, 731-738. https:// doi.org/10.1016/j.lwt.2015.09.002

Shalin, T., Sindhu, R., Binod, P., Soccol, C.R. and Pandey, A. (2014). Mixed Cultures Fermentation for the Production of Poly-ß-hydroxybutyrate. Brazilian Archives of Biology and Technology, 57(5), 644-652. https://doi.org/10.1590/S1516-89132013005000016

Sroka, Z., Janiak, M. and Dryś, A. (2015). Antiradical activity and amount of phenolic compounds in extracts obtained from some plant raw materials containing methylxanthine alkaloids. Herba Polonica, 61(3), 53-66. https://doi.org/10.1515/hepo-
2015-0022

Sudarmadji, S., Haryono, B. and Suhardi. (2007). Analisa Bahan Makanan dan Pertanian. Hal: 1-172. Yogyakarta: Liberty Yogjakarta Bekerja Sama dengan Pusat Antar Universitas Pangan dan Gizi Universitas Gajah Mada. [In Bahasa Indonesia].

Todorovic, V., Redovnikovic, I.R., Todorovic, Z., Jankovic, G., Dodevska, M. and Sobajic, S. (2015). Polyphenols, methylxanthines, and antioxidant capacity of chocolates produced in Serbia. Journal of Food Composition and Analysis, 41, 137-143. https://doi.org/10.1016/j.jfca.2015.01.018

Utami, R.R., Armunanto, R., Rahardjo, S. and Supriyanto. (2016). Effects of cocoa bean (Theobroma cocoa L.) fermentation on phenolic content, antioxidant activity, and functional group of cocoa bean shell. Pakistan Journal of Nutrition, 15 (10), 948-953. https://doi.org/10.3923/ pjn.2016.948.953

Vodnar, D.C., Paucean, A., Dulf, F.V. and Socaciu, C. (2010). HPLC Characterization of Lactic Acid Formation and FTIR Fingerprint of Probiotic Bacteria during Fermentation Processes. Notulae Botanicae Horti Agrobotanici Cluj-Napoca, 38(1), 109-113. https://doi.org/10.15835/nbha3824752 